\title{
Sneak Peek into Tobacco Habits and Associated Insidious Oral Lesions in an Odisha Sample Population
}

\author{
Shibani Das, Sadhana Shenoy*
}

\begin{abstract}
Background: Tobacco use in various forms, including with Areca nut, causes several potentially malignant disorders. Many lesions may transform into oral squamous cell carcinoma. Although patients may be aware of the hazards of tobacco habits, the lesions by themselves are insidious in nature resulting in failure of patients to present to general dentists/specialists at early stages. Our aim was to study the types of habits prevalent in the region of Rourkela in Orissa and to assess the insidious nature of the lesions associated with these habits. Not many studies have been done from this part of India. Materials and Methods: A camp was conducted for habitual users of tobacco and its products, Areca nut and other mixed habit users. A thorough history was taken of the type, duration and frequency of habits, symptoms of patients along with clinical examination by

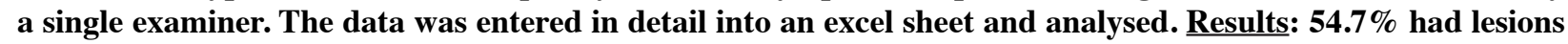
and $60.9 \%$ of them were asymptomatic and rest had mild burning sensation while eating. There was a very low awareness of the presence of lesions among the patients. Conclusions: There is a need to spread the awareness of the ill effects of the tobacco and other associated habits far and wide and more importantly educate the general public on the appearance of associated lesions as these are almost always insidious in nature. The patients can self-examine, detect lesions early when present and approach the dentist at the earliest opportunity.
\end{abstract}

Keywords: Tobacco habits - areca nuts - insidious oral lesions - awareness

Asian Pac J Cancer Prev, 16 (16), 7007-7009

\section{Introduction}

The hazards of tobacco and its products (smoked and smokeless forms), areca nut (in various processed and unprocessed forms) etc. has been discussed at length in the past in various studies nationally (Acharya et al., 2014; Chandroth et al., 2014; Sankeshwari et al., 2015) and internationally (Al-Attas et al., 2014; Al-Maweri et al., 2014). The oral effects of such habits, though varied, are significantly related to occurrence of potentially malignant disorders like oral leukoplakia, erythroplakia, oral submucous fibrosis and malignant lesions like oral squamous cell carcinoma.

India is a culturally diverse country and the consumption pattern of various forms of tobacco and areca nut are equally diverse. There haven't been many studies done on habits and associated lesions in Orissa. The aim of our study was to have a sneak peek into the types of habits seen in this part of India and their effects on the oral mucosa.

\section{Materials and Methods}

This study was conducted at a camp in Rourkela for patients who used any form of tobacco or areca nut. A detailed history was collected from all patients with in depth assessment of the type of habit/habits, duration of habit and frequency of the habit. History of any burning sensation or difficulty in mouth opening was noted. A thorough clinical examination was conducted by a single investigator. The type and severity of lesion was noted along with any additional significant findings. The patients were advised to visit the local hospital for biopsy and further follow up after counselling for cessation of habits.

The details of the habits in these patients is mentioned in Table 1. Presence of burning sensation and presence of any lesion was compared with each of the habits. The data were statistically analysed using Chi-square/ Fisher Exact test.

\section{Results}

A total of 64 patients visited the camp. These included Table 1. Habits of Patients Studied

\begin{tabular}{lc}
\hline Habit & No. of patients \\
\hline Gudakhu & 11 \\
Gutkha & 47 \\
Khaini & 40 \\
Pan chewing & 32 \\
Smoking cigarette & 13 \\
Smoking cigarette and bidi & 2 \\
Smoking bidi & 1 \\
Alcohol & 4 \\
\hline
\end{tabular}


Table 2. Burning Sensation

\begin{tabular}{lrrr}
\hline Burning sensation & \multicolumn{2}{c}{ Gender } & Total \\
\cline { 2 - 3 } & Female & Male & \\
\hline No & $2(40 \%)$ & $37(62.7 \%)$ & $39(60.9 \%)$ \\
Yes & $3(60 \%)$ & $22(37.3 \%)$ & $25(39.1 \%)$ \\
Total & $5(100 \%)$ & $59(100 \%)$ & $64(100 \%)$ \\
\hline
\end{tabular}

Table 3. Presence or Absence of Lesion

\begin{tabular}{lrrr}
\hline \multirow{2}{*}{ Presence or absence of lesion } & \multicolumn{2}{c}{ Gender } & \multirow{2}{*}{ Total } \\
\cline { 2 - 3 } & \multicolumn{1}{c}{ Female } & \multicolumn{1}{c}{ Male } & \\
\hline No lesions & $3(60 \%)$ & $26(44.1 \%)$ & $29(45.3 \%)$ \\
Geographic tongue & $0(0 \%)$ & $2(3.4 \%)$ & $2(3.1 \%)$ \\
Leukoplakia & $1(20 \%)$ & $10(16.9 \%)$ & $11(17.2 \%)$ \\
Lichenoid reaction & $0(0 \%)$ & $6(10.2 \%)$ & $6(9.4 \%)$ \\
OSF grade 1 & $1(20 \%)$ & $8(13.6 \%)$ & $9(14.1 \%)$ \\
Speckled Leukoplakia & $0(0 \%)$ & $2(3.4 \%)$ & $2(3.1 \%)$ \\
Tobacco pouch keratosis & $0(0 \%)$ & $6(10.2 \%)$ & $6(9.4 \%)$ \\
Total & $5(100 \%)$ & $59(100 \%)$ & $64(100 \%)$ \\
& & & \\
\hline
\end{tabular}

59 males and 5 females in the age group of 15-70 years. Use of Gutkha, Pan chewing, Khaini, Gudakhu, Bidi/ cigarette smoking were the various prevalent habits. (Table 1). Majority of them had a combination of habits. Only 14 of them had a single habit ( 7 had Gutkha habit alone, 4 had Khaini habit alone and 1 each had Pan chewing, Gudakhu and Smoking habit alone). 65.6\% of them had tobacco, areca nut and slaked lime as the constituents. $39.1 \%$ of the patients had burning sensation (Table 2). Of these, $73.4 \%$ were Gutkha users followed by Khaini users. $54.7 \%$ of the people had some form of oral lesion (Table $3)$. There was no statistical significance seen between type of habits and burning sensation and type of habits and presence of lesions.

\section{Discussion}

A plethora of studies exist on the prevalence of habits in various parts of India. However not many studies have been done in this part of the country. Before looking for the overall prevalence in this part of the country we decided to do a pilot study to evaluate the type, duration and frequency of habits here.

Patients with a combination of above mentioned habits are frequently found in the Indian population and are considered to be at a higher risk of developing oral lesions due to the added and prolonged exposure to carcinogens (Aruna et al, 2011). In our study too majority of patients had combination of habits. In such situations, it is difficult to know the independent effect of each habit. Chewing habit, like smoking, has been proven to be associated with premalignant oral lesions (Kavarodi et al., 2014). Majority of the habits seen here were similar to the habits seen in other parts of the country with chewers exceeding smokers. $4.7 \%$ of the people used Gudakhu. They usually used it two times/day. 'Gudakhu' is a paste-like tobacco preparation used widely in Orissa and neighbouring states of India. During use it is rubbed over the teeth and gum with a fingertip. Besides tobacco, it contains molasses, lime, red soil and water (Das et al., 1992).

Irrespective of whether these people were long time users or recent users, taking into consideration both duration and frequency of the habits, oral lesions were noted in them. Though more than half of the people with habits had oral lesions, majority were unaware of the lesion. Lack of awareness among people could be attributed to lack of education about the habits and their harmful effects, misconception that they cause only lung cancer etc. Oral cavity being a highly accessible area, mouth self-examination may be used as an effective tool to improve the awareness of oral cancer and for the early detection of lesions (Elango et al., 2011). The aim is to encourage the high-risk individuals to perform oral examination by themselves, in front of a mirror under good light, and to seek medical attention if they find an abnormality (Mathew et al., 1995). In this study, patients were unaware of the presence of any lesions as they were asymptomatic or only mildly symptomatic. Burning sensation and difficulty in mouth opening were the common symptoms noted. However, the mild nature of these symptoms prevented them from approaching any physician/dentist.

We tried to find out the association of these habits with burning sensation and found that there was no statistically significant difference.

We hereby emphasise the insidious nature of the dreadful effects that these habits have on the oral mucosa. As, many of the lesions are asymptomatic or only mildly symptomatic, many a times these go unnoticed till they reach advanced stages. Prevention is the key to better oral health. There are statutory warnings, cancer pictures on some of the packets of tobacco products and so on but in vain. People continue with the habits as most of them believe they will not be the ones to be affected by any disease.

The warnings should be given in regional languages for majority of the people to understand the content (Oswal et al., 2011). Pictorial form of representing the dangerous effects of tobacco/arecanut use is more effective than just a text form (Karibasappa et al., 2011). However, in one study, approximately $90 \%$ of the participants had never noticed statutory warnings on tobacco and alcohol products. Awareness was especially poor in people of lower socio-economic status. It was highlighted that there is a need for education concerning the risk factors for oral cancer, its clinical manifestations and the impact of adverse habits on long term health (Sankeshwari et al., 2015). Compared to never smokers, established smokers were more aware of the warning labels and talked about them more (White et al., 2008). Further, the magnitude of the effects, the dangers are not understood by general public. Incorporation of information on how to quit can be given if any. The uneducated, the rural population also have to be aware of the ill effects of tobacco.

Generally it has been seen that people who have habits have some family history of its use/ close association with peers who use. Education in a simplified manner in school would help. Misconceptions like - Small amounts is ok, Only 1 habit is ok are not acceptable. Habits in any form is not an acceptable behaviour and we need to bring about a change in the mind set of individuals. Efforts to ban these products are on but are taking a step back because of the 
attitude of the tobacco industry. Ban is a must because just as the doctors based on their knowledge take decisions on the kind of treatment that the patient would require, it is up to the government to decide for the nation by banning them in the best interest of the health of all.

In conclusion, Oral effects of various habits have already been well established with lot of ongoing research in this field. There is enough proof to say that habits can cause potentially malignant and malignant disorders in the oral cavity. However, the findings of these research is not reaching the general public as observed in our study. Majority were unaware of presence of lesions or even the need to visit the dentist for any mild symptoms that they had. The focus should now be on how effectively this information can be projected in the right way to people irrespective of age, economic status, education etc. Instead of waiting for the government to take action, each one of the health care professionals can create awareness in the neighbouring areas and the rural population can be covered through regular camps. especially on the initial clinical presentation of the potentially malignant disorders like leukoplakia, erythroplakia and oral submucous fibrosis.

'Every small step taken by each one of us will be a giant leap for mankind in the prevention of cancer'

\section{References}

Acharya S, Pentapati KC, Acharya S (2014). Socioeconomic mobility and tobacco consumption patterns in fish industry workers in Udupi District of coastal Karnataka. Indian J Dent Res, 25, 653-6.

Al-Attas SA, Ibrahim SS, Amer HA, Darwish Zel-S, Hassan MH (2014). Prevalence of potentially malignant oral mucosal lesions among tobacco users in Jeddah, Saudi Arabia. Asian Pac J Cancer Prev, 15, 757-62.

Al-Maweri SA, Alaizari NA, Al-Sufyani GA (2014). Oral mucosal lesions and their association with tobacco use and qat chewing among Yemeni dental patients. J Clin Exp Dent, 6, 460-6.

Aruna DS, Prasad KV, Shavi GR, et al (2011). Retrospective study on risk habits among oral cancer patients in karnataka cancer therapy and research institute, Hubli, India. Asian Pac $J$ Cancer Prev, 12, 1561-6.

Chandroth SV, Venugopal HK, Puthenveetil S, et al (2014). Prevalence of oral mucosal lesions among fishermen of Kutch coast, Gujarat, India. Int Marit Health, 65, 192-8.

Dash BC, Das RK (1992). Genotoxicity of 'gudakhu', a tobacco preparation. I. In mice in vivo. Mutat Res, 280, 45-53.

Elango KJ, Anandkrishnan N, Suresh A, et al (2011). Mouth self-examination to improve oral cancer awareness and early detection in a high-risk population. Oral Oncol, 47, 620-4.

Karibasappa GN, Nagesh L, Usha GV, Prakash S (2011). Assessment of awarenesss about pictorial warnings on tobacco products among 15 years and above age in Davangere city, Karnataka, India - A cross sectional survey. Indian J stomatal, 2, 227-32.

Kavarodi AM, Thomas M, Kannampilly J (2014). Prevalence of oral pre-malignant lesions and its risk factors in an indian subcontinent low income migrant group in qatar. Asian Pac J Cancer Prev, 15, 4325-9.

Mathew B, Sankaranarayanan R, Wesley R, Nair MK (1995). Evaluation of mouth self-examination in the control of oral cancer. Br J Cancer, 71, 397-9.

Oswal KC, Raute LJ, Pednekar MS, Gupta PC (2011). Are current tobacco pictorial warnings in india effective? Asian Pac J Cancer Prev, 12, 121-4.

Sankeshwari R, Ankola A, Hebbal M, Muttagi S, Rawal N (2015). Awareness regarding oral cancer and oral precancerous lesions among rural population of Belgaum district, India. Glob Health Promot, [Epub ahead of print].

White V, Webster B, Wakefield M (2008). Do graphic health warning labels have an impact on adolescents' smokingrelated beliefs and behaviours? Addiction, 103, 1562-71. 